\title{
Effect of mesoporous silica nanoparticles co-loading with 17-AAG and Torin2 on anaplastic thyroid carcinoma by targeting VEGFR2
}

\author{
CONGCONG WANG ${ }^{1 *}$, RUIGUO ZHANG ${ }^{1 *}$, JIAN TAN $^{1}$, ZHAOWEI MENG $^{1}$, \\ YUEQIAN ZHANG ${ }^{1}$, NING LI ${ }^{1}$, HANJIE WANG $^{2}$, JIN CHANG ${ }^{2}$ and RENFEI WANG ${ }^{1}$ \\ ${ }^{1}$ Department of Nuclear Medicine, Tianjin Medical University General Hospital, \\ Tianjin 300052; ${ }^{2}$ Institute of Nanobiotechnology, School of Materials Science and Engineering, \\ Tianjin Key Laboratory of Composites and Functional Materials, Tianjin University, Tianjin 300072, P.R. China
}

Received July 21, 2019; Accepted February 19, 2020

DOI: $10.3892 /$ or.2020.7537

\begin{abstract}
Anaplastic thyroid carcinoma (ATC) is a highly aggressive tumor with a poor prognosis and a low median survival rate because of insufficient effective therapeutic modalities. Recently, mesoporous silica nanoparticles (MSNs) as a green non-toxic and safe nanomaterial have shown advantages to be a drug carrier and to modify the targeting group to the targeted therapy. To aim of the study was to explore the effects of MSNs co-loading with 17-allylamino-17-demethoxy-geldanamycin (17-AAG; HSP90 inhibitor) and 9-(6-aminopyridin-3-yl)-1-(3-(trifluoromethyl) phenyl)benzo[h][1,6]naphthyridin-2(1H)-one (Torin2; mTOR inhibitor) by targeting vascular endothelial growth factor receptor 2 (VEGFR2) on the viability of human anaplastic thyroid carcinoma FRO cells. The cytotoxicity of 17-AAG and Torin 2 were analyzed by MTT assay. The possible synergistic antitumor effects between 17-AAG and Torin2 were evaluated by CompuSyn software. Flow cytometry was performed to assess the VEGFR2 targeting of (17-AAG+Torin2)@ MSNs-anti-VEGFR2 ab and uptake by FRO cells. An ATC xenograft mouse model was established to assess the antitumor effect of (17-AAG+Torin2)@MSNs-anti-VEGFR2 ab in vivo. The results revealed that the combination of 17-AAG and Torin 2 inhibited the growth of FRO cells more effectively compared with single use of these agents. Additionally, the synergistic antitumor effect appeared when concentration ratio of the two drugs was 1:1 along with total drug concentration greater than $0.52 \mu \mathrm{M}$. Furthermore, in an ATC animal model, it
\end{abstract}

Correspondence to: Dr Renfei Wang, Department of Nuclear Medicine, Tianjin Medical University General Hospital, 154 Anshan Road, Heping, Tianjin 300052, P.R. China

E-mail: roslyn_en@163.com

*Contributed equally

Key words: anaplastic thyroid carcinoma, vascular endothelial growth factor receptor 2, molecular targeted drugs, drug combination therapy, resistance, nanoparticles was revealed that the (17-AAG+Torin2)@MSNs-anti-VEGFR2 ab therapy modality could most effectively prolong the median survival time [39.5 days vs. 33.0 days (non-targeted) or 27.5 days (control)]. Compared to (17-AAG+Torin2)@MSNs, the (17-AAG+Torin2)@MSNs-anti-VEGFR2 ab could not only inhibit ATC cell growth but also prolong the median survival time of tumor-bearing mice in vivo and vitro more effectively, which may provide a new promising therapy for ATC.

\section{Introduction}

Anaplastic thyroid carcinoma (ATC) is one of the most aggressive endocrine neoplasms, which has a high mortality rate despite the fact that ATC only accounts for $2 \%$ of all thyroid cancers (1). The median survival period of patients with ATC is less than half a year, and the 1-year survival rate is less than $20 \%$ after diagnosis (2-4). However, many patients spend money and ultimately succumb to ATC due to dismal prognosis, incurability, side effects, and complexity of treatment (5).

Vascular endothelial growth factor receptor 2 (VEGFR2) is a cell membrane receptor that plays a critical role in the process of transforming precancerous lesions into malignant tumors with growth and metastasis (6). At present, evidence has revealed that the overexpression of VEGFR is closely associated with poor prognosis and tumor metastasis in numerous highly aggressive cancers including lung, cervical and thyroid cancer as well as glioblastoma (7-9). In addition, several VEGFR inhibitors (sorafenib, vandetanib, axitinib, and cabozantinib) have been evaluated to treat advanced thyroid cancers for their ability to block angiogenesis involved in the process of local invasion and metastasis (1).

Molecular chaperone, especially heat shock protein 90 (HSP90) has been confirmed as an effective anticancer treatment. The overexpression of HSP90 has been revealed in numerous human malignancies, and correlated with aggressive biological behaviors, poor survival rates, as well as with the genesis and progression of tumors (10-12). In fact, the first inhibitor to act on HSP90, 17-allylamino-17-demethoxygeldanamycin (17-AAG) has shown great promise with significant biological activity, and its clinical derivatives are widely used as anticancer drugs (13-15). 
PI3-kinase proteins, such as mammalian target of rapamycin (mTOR) have been revealed to control cell growth, survival, proliferation, and migration in human cancers, including ATC $(16,17)$. The mTOR pathway has been revealed to be over-activated in thyroid cancer $(18,19)$. 9-(6-Aminopyridin-3-yl)-1-(3-(trifluoromethyl)phenyl)benzo[h] $[1,6]$ naphthyridin-2(1H)-one (Torin2), as a second-generation mTOR inhibitor, has been gaining attention in the last few years for antitumor drug development due to the dual inhibition effect of mTORC1 and mTORC2 $(16,18)$.

However, most anticancer drugs still have some disadvantages, such as poor solubility, inefficient cellular uptake, dose-limiting toxicity, and low bioavailability $(15,20)$. Silica, an endogenous substance, which is abundant in bone tissue, is considered 'generally safe' by the U.S. Food and Drug Administration (FDA) $(21,22)$. Currently, the FDA has approved silica nanoparticle-based drugs for human phase I clinical trials (23). Among numerous silica materials, mesoporous silica nanoparticles (MSNs) have been widely investigated for biomedical applications such as controlled drug delivery, tissue engineering, and biological imaging especially as a tool for diagnosis and treatment of tumors $(21,24,25)$. In the present study, mesoporous silica nanoparticles (MSNs) were used as a biocompatible drug delivery system, which could increase the solubility of water-soluble drugs, enhance their bioavailability and reduce toxicity of normal tissues $(4,26,27)$.

Inspired by the key role of the VEGFR signaling pathway in tumor growth, metastasis, and the advantages provided by MSNs, in this study, a new 2-in-1 MSNs targeting VEGFR2, containing 17-AAG and Torin2 was constructed. The present study was designed to investigate whether MSNs can be used as a delivery vector for anticancer drugs and to evaluate the effects of (17-AAG+Torin2)@MSNs-anti-VEGFR2 ab on ATC tumor growth.

\section{Materials and methods}

Cell culture. The Nthy-ori 3-1 normal human thyroid cell line and the FRO anaplastic thyroid carcinoma cell line (a non-metastatic cell line) were purchased from the Cell Resource Center of the Institute of Basic Medical Sciences, Beijing Medical College, Peking Union Medical College, China. FRO cells were inoculated into Dulbecco's modified Eagle's medium (DMEM) supplemented with $10 \%$ fetal bovine serum (FBS) (both from Gibco; Thermo Fisher Scientific, Inc.), $100 \mathrm{M} / \mathrm{ml}$ streptomycin and $100 \mathrm{U} / \mathrm{ml}$ penicillin (both from Sigma-Aldrich; Merck KGaA). The Nthy-ori 3-1 cells were grown in F12K medium (Gibco; Thermo Fisher Scientific, Inc.) supplemented with $10 \%$ FBS, $100 \mathrm{M} / \mathrm{ml}$ streptomycin, $100 \mathrm{U} / \mathrm{ml}$ penicillin. A $75-\mathrm{cm}^{2}$ cell culture flask was then placed in a humidified incubator (Thermo-Forma; Thermo Fisher Scientific, Inc.) with $5 \% \mathrm{CO}_{2}$ at $37^{\circ} \mathrm{C}$. Cells at $\sim 80 \%$ confluence were used in subsequent experiments.

Cell viability assay. Cell viability was determined by the 3-(4,5-dimethylthiazol-2-yl)-2,5-diphenyltetrazolium bromide (MTT, Sigma-Aldrich: Merck KGaA) assay $(28,29)$. FRO cells in logarithmic phase $\left(2.5 \times 10^{3}\right.$ cells/well $)$ were inoculated into a 96-well plate. Cells were cultured and divided into six groups: $17-\mathrm{AAG}$-treated $(0.1,0.2,0.5,1,2$, and $5 \mu \mathrm{M})$ cells;
Torin2-treated $(0.1,0.2,0.5,1,2$, and $5 \mu \mathrm{M})$ cells; Torin2 $(0.1$, $0.2,0.5,1,2$, and $5 \mu \mathrm{M}$ ) combined with 17-AAG-treated (the concentration ratio of 17-AAG and Torin2 was 1:1) cells; Torin2 $(0.1,0.2,0.5,1,2$, and $5 \mu \mathrm{M})$ combined with $17-A A G-t r e a t e d$ (the concentration ratio of 17-AAG and Torin2 was 2:1) cells; negative control groups (cells were treated with DMSO as a control), and blank control groups. After incubation with the drugs for various time-points, $20 \mu \mathrm{l}$ MTT was added to each well and incubation continued for $2 \mathrm{~h}$ at $37^{\circ} \mathrm{C}$. Finally, the optical density (OD) was measured at $492 \mathrm{~nm}$ using a 96-well microplate reader (Bio Tek Instruments). Cell viability $(\%)=[(\mathrm{OD}$ of experiment group-OD of blank group)/(OD of negative control group-OD of blank group)] x $100 \%$. All experiments were in the triplicate model.

Drug combination analysis. The combined effects of various concentrations and ratios of 17-AAG and Torin 2 were assessed using CompuSyn software (www.combosyn.com). The combination index (CI) was assessed according to the Chou-Talalay method (30). In brief, a CI value which was $<1$, equaled to 1 , or $>1$ indicated a synergistic effect, an additive effect and antagonistic effect, respectively.

Synthesis of MSNs and modification. The synthesis of mesoporous silica nanoparticles (MSNs) was performed as previously reported $(4,31)$. Briefly, cetyltrimethyl ammonium bromide (CTAB; Sigma-Aldrich; Merck KGaA) was dissolved in a solution of water $(25 \mathrm{ml})$, ethanol $(5 \mathrm{ml})$, and caustic soda solution $(100 \mu \mathrm{l} ; 2 \mathrm{M})$ and heated to $75^{\circ} \mathrm{C}$ under vigorous stirring conditions. Then, tetraethyl orthosilicate (TEOS; $200 \mu \mathrm{l}$; Sigma-Aldrich; Merck KGaA) was added dropwise and mixed at $75^{\circ} \mathrm{C}$ for $2 \mathrm{~h}$. Next, the reaction solution was centrifuged (11,000 x g, $10 \mathrm{~min})$, washed several times with ethanol, and dried in a vacuum oven at $60^{\circ} \mathrm{C}$ for $12 \mathrm{~h}$. After removal of surfactant template (CTAB), MSNs were obtained. Finally, MSNs were ultrasonically dispersed in a solution of dimethyl sulfoxide (DMSO; $5 \mathrm{ml}$ ); and 3-aminopropyltriethoxysilane (APTES; $100 \mu \mathrm{l}$; Sigma-Aldrich; Merck KGaA), stirred at $24^{\circ} \mathrm{C}$ for $12 \mathrm{~h}$. The product of MSNs- $\mathrm{NH}_{2}$ was separated by centrifugation $(11,000 \mathrm{x} \mathrm{g}, 10 \mathrm{~min})$, washed several times by ethanol, and dried in a vacuum at room temperature overnight.

Characterization of nanoparticles. Transmission electron microscope (TEM; JEOL-100CXII) was used to determine the morphology and size of the nanoparticles [MSNs, (17-AAG+Torin2)@MSNs, and (17-AAG+Torin2)@ MSNs-anti-VEGFR2 ab]. Briefly, nanoparticles were dissolved in PBS solution (10 mM, pH 7.4) and one drop of fully diluted nanoparticle suspension was deposited on a carbon-coated copper grid, and dried at room temperature for $36 \mathrm{~h}$. Then, TEM images were captured at $200 \mathrm{kV}$ accelerating voltage. The hydrodynamic sizes of nanoparticles were assessed by dynamic light scattering (DLS) using a Zetasizer (Nano ZS90; Malvern Instruments, Ltd.).

Flow cytometric analysis. The binding of (17-AAG+Torin2)@ MSNs and (17-AAG+Torin2)@MSNs-anti-VEGFR2 ab to target FRO cells was detected by flow cytometry (32). FRO cells ( $5 \times 10^{6}$ cells) were seeded into a cell culture flask and grown to 80-90\% confluence. A 1-ml solution of (17-AAG+Torin2)@ 
MSNs and (17-AAG+Torin2)@MSNs-anti-VEGFR2 ab ( $1 \mathrm{mg} / \mathrm{ml}$, labeled with FITC) each was added to the flask. Then, the cells were cultured for $0.5,3$ and $8 \mathrm{~h}$, respectively. Subsequently, the supernatant was discarded and the sediment was washed thoroughly with PBS 3-4 times before digestion with trypsin. After centrifugation at $0.5 \mathrm{x}$ g for $5 \mathrm{~min}$ at room temperature, $300 \mu \mathrm{l}$ of formaldehyde was added. Finally, a BD FACSCalibur flow cytometer (BD Biosciences), equipped with a 490-nm laser source was used to analyze the cells.

In vitro cytotoxicity of (17-AAG+Torin2)@MSNs-anti$V E G F R 2 a b$. In order to further assess the effectiveness of VEGFR2-targeted chemotherapy of (17-AAG+Torin2)@ MSNs-anti-VEGFR2 ab in vitro, human anaplastic thyroid carcinoma FRO cells which was high VEGFR2 expression were selected as the cell category and were treated with free (17-AAG+Torin2), or an equivalent dose of (17-AAG+Torin2) loaded into either MSNs or MSNs-anti-VEGFR2 ab (nanoparticles were diluted in complete media) for $48 \mathrm{~h}$, and cell viability was determined by a MTT assay.

Tumor xenografts in nude mice and in vivo experimentation; $(33,34)$. Female nude mice (Balb/c, 4 weeks) were obtained from the Beijing Experimental Animal Research Center at Peking Union Medical College and housed in the Laboratory Animal Center of Tianjin Medical University with a constant temperature $\left(21-25^{\circ} \mathrm{C}\right.$ ) and permissible relative humidity $(40-60 \%)$. The female nude mice $(n=18)$ were inoculated with FRO cells $(5,000,000$ cells per mouse) in the subcutaneous tissue under the shoulder, and when the tumor diameter of the nude mice reached $\sim 10 \mathrm{~mm}$, the mice were randomly divided into three groups and were administered an intra-tumoral injection of normal saline, (17-AAG+Torin2)@MSNs or (17-AAG+Torin2)@MSNs-anti-VEGFR2 ab (nanoparticles were diluted in a medium with saline). Mice were weighed every three days, and the tumor volumes were measured at the same time. The tumor volume was determined using the following formula: The tumor volume $=4 \pi / 3 \times(1 / 2$ length $\mathrm{x} 1 / 2$ height $\mathrm{x} 1 / 2$ width) (4). The mice pentobarbital sodium anesthesia $(50 \mathrm{mg} / \mathrm{kg})$ and complete cardiac arrest as the standard for death if they were unable to eat or lost $>20$ percent of their body weight or had tumors $>20 \mathrm{~mm}$ in diameter. All animal experimental procedures were performed with strict accordance with guidelines approved by the Institutional Animal Experiments Ethics Committee of Tianjin Medical University General Hospital.

Histopathology and immunohistochemistry. An immunohistochemical experiment was performed with the following antibodies: A rabbit primary Ki-67 antibody (cat. no. A700-021; Thermo Fisher Scientific, Inc.) at a dilution of 1:200, a goat anti-rabbit secondary antibody (cat. no. A-11034; Thermo Fisher Scientific, Inc.) at a dilution of 1:500, a rat anti-mouse CD34 antibody (cat. no. 551387; BD Biosciences) at a dilution of 1:400, and a goat anti-rat secondary antibody (cat. no. 554017; BD Biosciences) at a dilution of 1:800. Briefly, 5-mm thick paraffin-embedded sections were first dewaxed in xylene and the slides were then washed with ethanol. Thereafter, the sections ware washed several times by PBS. Endogenous blocking was blocked with
$3 \% \mathrm{H}_{2} \mathrm{O}_{2}$ and then blocked with protein blocking solution (1\% normal goat serum and 5\% normal horse serum). The sections were then incubated overnight at $4{ }^{\circ} \mathrm{C}$ with a primary antibody, washed with PBS three times and then incubated at $37^{\circ} \mathrm{C}$ for $1 \mathrm{~h}$ with a secondary antibody. The sections were then washed three times with PBS and then incubated with DAKO-REAL ${ }^{\mathrm{TM}}$ En-Vision ${ }^{\mathrm{TM}}$ detection system (Dako) for $1 \mathrm{~h}$, and then counterstained with Mayer's hematoxylin (Thermo Fisher Scientific, Inc.) and visualized using diaminobenzidine (Thermo Fisher Scientific, Inc.)

Statistical data analysis. Each experiment was repeated three times in order to ensure the accuracy of the experimental results, except for special instructions. SPSS software (SPSS 15.0; SPSS, Inc.) was used for data analysis, and ANOVA statistical analysis followed by LSD post hoc test were used to compare different time-points in each concentration group, and results were expressed as the mean \pm standard deviation (SD). Animal survival data were analyzed using Kaplan-Meier curves and the log-rank test. $\mathrm{P}<0.05$ was considered to indicate a statistically significant difference.

\section{Results}

Inhibition effects of 17-AAG and Torin2 on FRO cell proliferation in vitro. An MTT assay was conducted to evaluate the effects of 17-AAG and Torin2 on FRO cell proliferation. The results indicated that $17-\mathrm{AAG}$ or Torin2 markedly inhibited FRO cell proliferation in a time- and dose-dependent manner in the concentration range from 0.1 to $5 \mu \mathrm{M}(0.1,0.2,0.5,1,2$, and $5 \mu \mathrm{M})$ (Fig. $1 \mathrm{~A}$ and $\mathrm{B})$. The inhibition of cell proliferation was significantly increased by $17-\mathrm{AAG}$ and Torin 2 with increasing drug concentrations, especially in the concentration range of 0.1 to $1 \mu \mathrm{M}$ $(0.1,0.2,0.5,1 \mu \mathrm{M})$. The obtained half maximal inhibitory concentration $\left(\mathrm{IC}_{50}\right)$ of Torin 2 for $24,48,72 \mathrm{~h}$ was $3.44 \mu \mathrm{M}$, 0.81 and $0.27 \mu \mathrm{M}$, respectively. Concurrently, the $\mathrm{IC}_{50}$ of 17-AAG for $24,48,72 \mathrm{~h}$ was $65 \mu \mathrm{M}, 1.18$ and $0.35 \mu \mathrm{M}$, respectively. The cytotoxicity of Torin 2 on FRO cells was higher than 17-AAG when using the same concentration, thus, the ratios of $17-\mathrm{AAG}$ and Torin 2 selected may be 1:1, $2: 1$ or $3: 1$. Considering the economic costs, a ratio of $1: 1$ or 2:1 was finally adopted to investigate the synergy in the further experiment. The results of the cytotoxicity assay revealed that $17-\mathrm{AAG}$ or Torin2 treatment alone may inhibit FRO cell proliferation in vitro (Tables I and II).

Synergistic inhibitory effect of 17-AAG and Torin2 on anaplastic thyroid carcinoma cell growth. To assess the inhibitory effect of 17-AAG and Torin 2 on cell proliferation, FRO cells were incubated with increasing concentrations of the combination of 17-AAG and Torin 2 for $48 \mathrm{~h}$. As revealed in Fig. 1C, when 17-AAG and Torin2 were combined, FRO cell viability was markedly decreased. When the concentration ratio of 17-AAG and Torin2 was $1: 1$ or $2: 1$, the $\mathrm{IC}_{50}$ of FRO cell was 0.33 and $0.26 \mu \mathrm{M}$, respectively. At most concentrations, there were no significant differences in the inhibition of cell proliferation when comparing the concentration ratios of 17-AAG and Torin2 at 1:1 or 2:1 (Fig. 1C and Table III). Furthermore, the combination index (CI) was calculated using 
Table I. Viability of FRO cells treated with various concentrations of 17-AAG at different time-points (mean \pm SD, \%).

\begin{tabular}{lcccrrrr}
\hline Concentration $(\mu \mathrm{M})$ & $24 \mathrm{~h}(\%)$ & $48 \mathrm{~h}(\%)$ & $72 \mathrm{~h}(\%)$ & $\mathrm{F}(\mathrm{P}-\text { value })^{\mathrm{a}}$ & $\mathrm{P}_{1}{ }^{\mathrm{b}}$ & $\mathrm{P}_{2}^{\mathrm{b}}$ & $\mathrm{P}_{3}^{\mathrm{b}}$ \\
\hline 0.1 & $87.51 \pm 4.01$ & $72.12 \pm 1.21$ & $63.83 \pm 2.43$ & $111.02(<0.01)$ & $<0.01$ & $<0.01$ \\
0.2 & $82.24 \pm 2.41$ & $67.79 \pm 1.32$ & $57.75 \pm 1.98$ & $238.12(<0.01)$ & $<0.01$ & $<0.01$ & $<0.01$ \\
0.5 & $78.42 \pm 3.89$ & $57.43 \pm 2.98$ & $44.93 \pm 1.43$ & $198.00(<0.01)$ & $<0.01$ & $<0.01$ & $<0.01$ \\
1 & $74.25 \pm 2.11$ & $51.82 \pm 2.43$ & $35.78 \pm 2.68$ & $383.69(<0.01)$ & $<0.01$ & $<0.01$ & $<0.01$ \\
2 & $71.37 \pm 2.01$ & $44.31 \pm 1.36$ & $32.44 \pm 2.34$ & $147.32(<0.01)$ & $<0.01$ & $<0.01$ & $<0.01$ \\
5 & $69.01 \pm 1.21$ & $39.92 \pm 2.43$ & $25.92 \pm 2.01$ & $201.32(<0.01)$ & $<0.01$ & $<0.01$ & $<0.01$ \\
\hline
\end{tabular}

${ }^{a}$ Analyzed by ANOVA. ${ }^{\mathrm{b}}$ Analyzed by a post hoc test (LSD method). $\mathrm{P}_{1}, 24$ vs. 48 h; $\mathrm{P}_{2}, 24$ vs. 72 h; $\mathrm{P}_{3}, 48$ vs. 72 h. 17-AAG, 17-allylamino-17-demethoxy-geldanamycin; ANOVA, analysis of variance; LSD, least significant difference.

Table II. Viability of FRO cells treated with various concentrations of Torin2 at different time-points (mean \pm SD, \%).

\begin{tabular}{lcccrrrr}
\hline Concentration $(\mu \mathrm{M})$ & $24 \mathrm{~h}(\%)$ & $48 \mathrm{~h}(\%)$ & $72 \mathrm{~h}(\%)$ & $\mathrm{F}(\mathrm{P}-\mathrm{value})^{\mathrm{a}}$ & $\mathrm{P}_{1}^{\mathrm{b}}$ & $\mathrm{P}_{2}^{\mathrm{b}}$ & $\mathrm{P}_{3}^{\mathrm{b}}$ \\
\hline 0.1 & $75.13 \pm 7.31$ & $68.89 \pm 2.14$ & $61.49 \pm 2.14$ & $12.87(<0.01)$ & 0.15 & 0.01 & 0.09 \\
0.2 & $65.48 \pm 2.40$ & $62.24 \pm 3.26$ & $49.72 \pm 2.63$ & $53.50(<0.01)$ & 0.20 & $<0.01$ & $<0.01$ \\
0.5 & $63.26 \pm 5.68$ & $52.67 \pm 4.00$ & $43.43 \pm 1.46$ & $33.78(<0.01)$ & 0.02 & $<0.01$ & 0.03 \\
1 & $61.42 \pm 1.13$ & $46.85 \pm 1.76$ & $35.12 \pm 1.02$ & $577.06(<0.01)$ & $<0.01$ & $<0.01$ & $<0.01$ \\
2 & $51.42 \pm 7.31$ & $42.52 \pm 1.14$ & $22.91 \pm 3.19$ & $59.00(<0.01)$ & 0.06 & $<0.01$ & $<0.01$ \\
5 & $48.11 \pm 4.84$ & $33.56 \pm 2.85$ & $11.91 \pm 2.15$ & $165.12(<0.01)$ & $<0.01$ & $<0.01$ & $<0.01$ \\
\hline
\end{tabular}

${ }^{\mathrm{a}}$ Analyzed by ANOVA. ${ }^{\mathrm{b}}$ Analyzed by a post hoc test (LSD method). $\mathrm{P}_{1}, 24$ vs. 48 h; $\mathrm{P}_{2}, 24$ vs. 72 h; $\mathrm{P}_{3}, 48$ vs. 72 h. Torin2, 9-(6-aminopyridin-3-yl)-1-(3-(trifluoromethyl)phenyl)benzo[h][1,6]naphthyridin-2(1H)-one; ANOVA, analysis of variance; LSD, least significant difference.
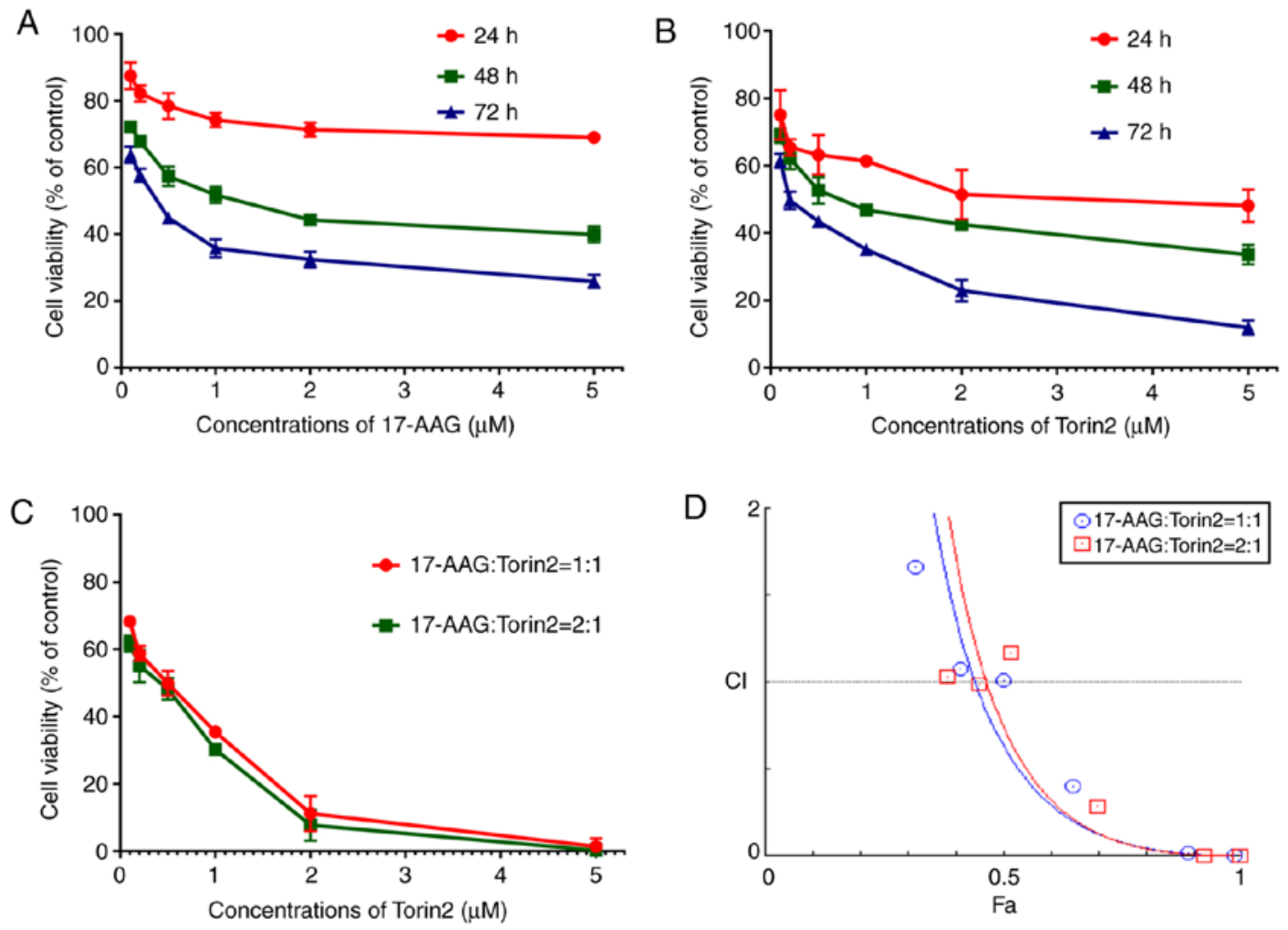

Figure 1. The cell viability of FRO cells treated with (A) 17-AAG only and (B) Torin 2 only, for 24, 48, and $72 \mathrm{~h}$. (C) The cell viability of FRO cells treated with 17-AAG and Torin2 at different concentrations and ratios for $48 \mathrm{~h}$. (D) The CI plot obtained from CompuSyn Report for 17-AAG and Torin2 combinations. 17-AAG, 17-allylamino-17-demethoxy-geldanamycin; Torin2 9-(6-aminopyridin-3-yl)-1-(3-(trifluoromethyl)phenyl)benzo[h][1,6]naphthyridin-2(1H)-one; CI, combination index. 
Table III. Cell inhibition rate after the combination of two drugs with various concentrations and at different ratios (mean \pm SD, $\%)$.

17-AAG:Torin2

\begin{tabular}{|c|c|c|c|c|}
\hline \multirow[b]{2}{*}{ Concentration of Torin $2(\mu \mathrm{M})$} & & \multirow[b]{2}{*}{ t-value } & \multirow[b]{2}{*}{ P-value } \\
\hline & $1: 1$ & $2: 1$ & & \\
\hline 0.1 & $31.64 \pm 1.24$ & $38.28 \pm 2.37$ & 6.08 & $<0.01$ \\
\hline 0.2 & $41.21 \pm 2.14$ & $44.88 \pm 4.81$ & 1.71 & 0.12 \\
\hline 0.5 & $50.11 \pm 3.69$ & $51.73 \pm 3.21$ & 0.81 & 0.44 \\
\hline 1 & $64.59 \pm 1.47$ & $69.78 \pm 1.23$ & 6.63 & $<0.01$ \\
\hline 2 & $88.87 \pm 5.21$ & $92.31 \pm 4.58$ & 1.21 & 0.25 \\
\hline 5 & $98.63 \pm 2.40$ & $99.75 \pm 1.86$ & 0.90 & 0.39 \\
\hline
\end{tabular}

${ }^{a}$ Analyzed by Student's t-test. 17-AAG, 17-allylamino-17-demethoxy-geldanamycin; Torin2, 9-(6-aminopyridin-3-yl)-1-(3-(trifluoromethyl) phenyl)benzo[h][1,6]naphthyridin-2(1H)-one.

CompuSyn software. A CI plot revealed that the combination of 17-AAG and Torin2 exhibited an antitumor effect at many points, which was a synergistic effect at play. Synergistic effects occurred $(\mathrm{CI}<1)$ in FRO cells when the total concentrations of the two drugs $>0.52 \mu \mathrm{M}$ (the ratio of 17-AAG and Torin2 was $1: 1$ ) or $0.79 \mu \mathrm{M}$ (the ratio of $17-\mathrm{AAG}$ and Torin2 was $2: 1$ ) (Fig. 1D). When the concentration ratio of 17-AAG and Torin2 was $1: 1$ or $2: 1$, the synergistic effects against FRO cells were not significantly different. Hence, in subsequent experiments the combination of 17-AAG $(1 \mu \mathrm{M})$ and Torin2 $(1 \mu \mathrm{M})$ was selected to ensure that it provided a gentle cytotoxic action but high synergy.

Synthesis and characterization of nanoparticles. MSNs, (17-AAG+Torin2)@MSNs, and (17-AAG+Torin2)@ MSNs-anti-VEGFR2 ab were successfully synthesized in the present study. The size and morphology of the three nanoparticles were assessed by DLS and TEM (Fig. 2). TEM images (Fig. 2A-C) revealed that the nanoparticles had good dispersion and ideal spherical shape. As revealed in Fig. 2D-F), DLS revealed that the average particle size of the nanoparticles was 135, 146, and $167 \mathrm{~nm}$, respectively. The particle size range was suggested to facilitate endocytosis. The mean zeta potential of nanoparticles was $-31.47,-30.21$, and $-5.04 \mathrm{mV}$, respectively. The changes in size and zeta potential after surface modification further demonstrated the successful attachment of the anti-VEGFR2 antibody on the surface of MSNs.

Determination of drug loading and encapsulation efficiency. 17-AAG and Torin2 were the chemotherapeutics in the treatment of ATC used by this study and combination therapy with the two drugs could directly eradicate established tumors. The standard curve of the Torin2/17-AAG concentration in DMSO was assessed by an Ultraviolet-Visible (UV-Vis) spectrophotometer at 317 or $355 \mathrm{~nm}$ (Fig. 3). The UV-Vis absorption spectrum revealed that the 17-AAG-loading capacity of (17-AAG+Torin2)@MSNs-anti-VEGFR2 ab was $7.29 \pm 0.23 \%$, and the encapsulation efficiency of $17-\mathrm{AAG}$ was $87.32 \pm 1.36 \%$. Similarly, the drug loading of Torin 2 was $6.15 \pm 0.64 \%$, and the encapsulation efficiency of Torin 2 was $86.23 \pm 2.15 \%$.
In vitro cellular uptake and VEGFR2 targeting. To assess whether the anti-VEGFR2 antibody maintains its binding specificity and affinity for VEGFR2 in combination with (17-AAG+Torin2)@MSNs, a systematic flow cytometric study was performed. The flow cytometric study revealed that (17-AAG+Torin2)@MSNs and (17-AAG+Torin2)@ MSNs-anti-VEGFR2 ab could bind to FRO cells efficiently (Fig. 4). In addition, as revealed in Fig. 4A and B), the uptake and the binding of (17-AAG+Torin2)@MSNs-anti-VEGFR2 ab were markedly higher than those of (17-AAG+Torin2)@ MSNs in FRO cells after 0.5 or $3 \mathrm{~h}$ incubation at $37^{\circ} \mathrm{C}$. However, the binding and uptake of (17-AAG+Torin2)@ MSNs-anti-VEGFR2 ab or (17-AAG+Torin2)@MSNs exhibited no significant change in FRO cells after $8 \mathrm{~h}$ of incubation (Fig. 4C). All the results indicated that (17-AAG+Torin2)@ MSNs-anti-VEGFR2 ab had highly specific binding in FRO cells.

Cellular cytotoxicity of (17-AAG+Torin2)@MSNs-antiVEGFR2 $a b$ in vitro. As revealed in Fig. 5A and Table IV, with increasing drug concentration, cell viability gradually decreased. In addition, (17-AAG+Torin2)@MSNs and (17-AAG+Torin2)@MSNs-anti-VEGFR2 ab groups displayed increased toxicity compared to the (17-AAG+Torin2) group on FRO cells $(\mathrm{t}=0.55-5.75, \mathrm{P}<0.05)$. In addition, the cell viability of the (17-AAG+Torin2)@MSNs-anti-VEGFR2 ab group was significantly decreased compared to the (17-AAG+Torin2)@ MSNs $(t=0.33-6.64, \mathrm{P}<0.05)$. Therefore, the results indicated that the (17-AAG+Torin2)@MSNs-anti-VEGFR2 ab could effectively inhibit the proliferation of FRO tumor cells and exhibited great potential for cancer therapy. Additionally, the inhibitory effect of (17-AAG+Torin2)@MSNs-anti-VEGFR2 ab on Nthy-ori 3-1 cells was also analyzed, which revealed low expression of VEGFR2 on its surface $(35,36)$ and FRO cells using the combination of 17-AAG $(1 \mu \mathrm{M})$ and Torin $2(1 \mu \mathrm{M})$. In Fig. $5 \mathrm{C}$, it was revealed that there was no significant difference in the cell viability of Nthy-ori 3-1 cells after $48 \mathrm{~h}$ of treatment with (17-AAG+Torin2)@MSNs and (17-AAG+Torin2)@ MSNs-anti-VEGFR2 ab. The results which revealed the higher cell viability of (17-AAG+Torin2)@MSNs-anti-VEGFR2 ab and (17-AAG+Torin2)@MSNs groups on Nthy-ori 3-1 cells (Fig. 5C) compared to FRO cells (Fig. 5B) confirmed the 
A
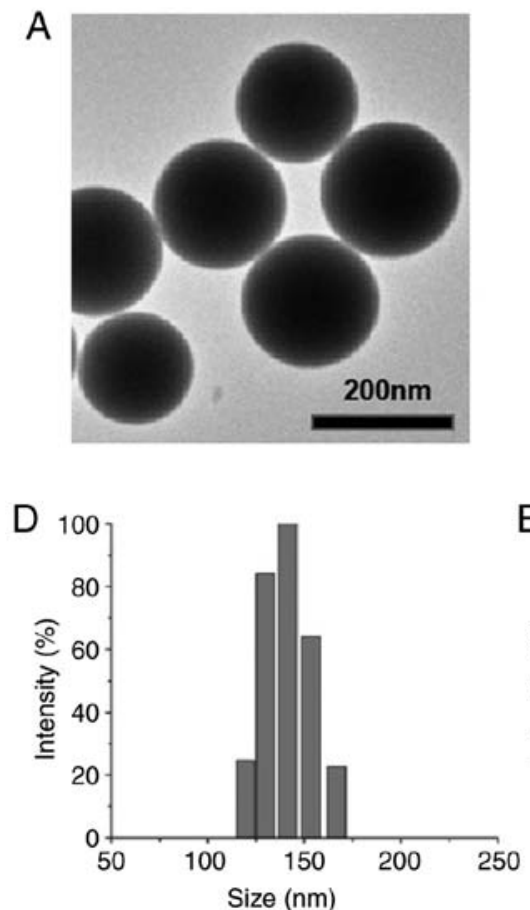

B
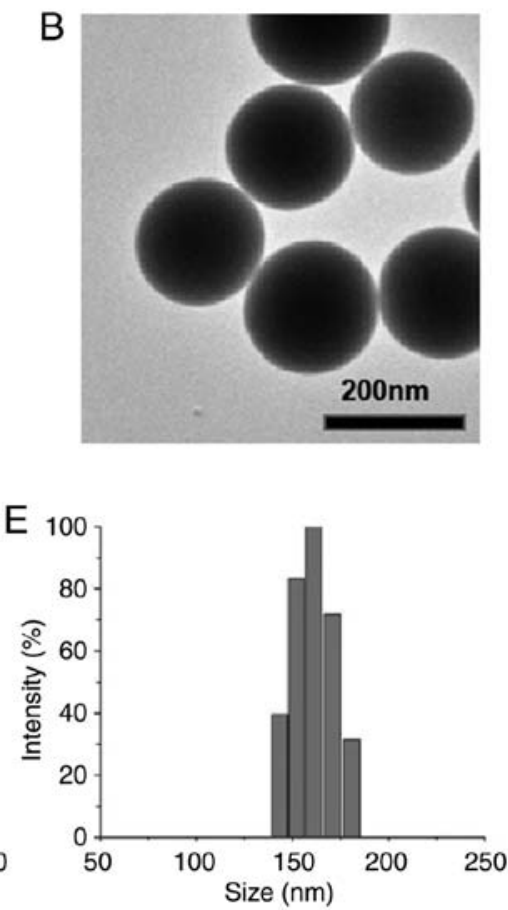

C

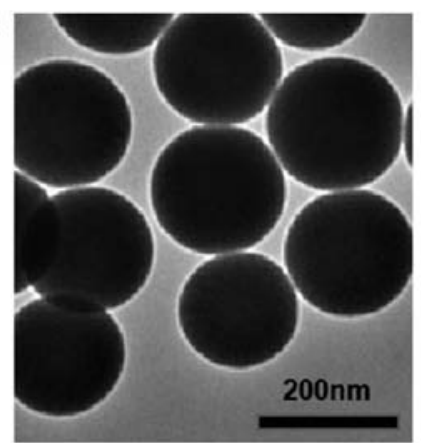

$\mathrm{F}$

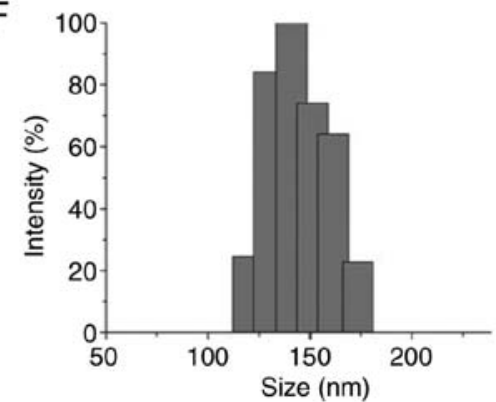

Figure 2. Characterization of synthesized nanoparticles. (A) TEM image of MSNs. (B) TEM image of (17-AAG+Torin2)@MSNs. (C) TEM image of (17-AAG+Torin2)@MSNs-anti-VEGFR2 ab. (D) Particle size of MSNs. (E) Particle size of (17-AAG+Torin2)@MSNs. (F) Particle size of (17-AAG+Torin2)@ MSNs-anti-VEGFR2 ab. TEM, transmission electron microscope; MSNs, mesoporous silica nanoparticles; 17-AAG, 17-allylamino-17-demethoxy-geldanamycin; Torin2 9-(6-aminopyridin-3-yl)-1-(3-(trifluoromethyl)phenyl)benzo[h][1,6]naphthyridin-2(1H)-one; VEGFR2, vascular endothelial growth factor receptor 2 .
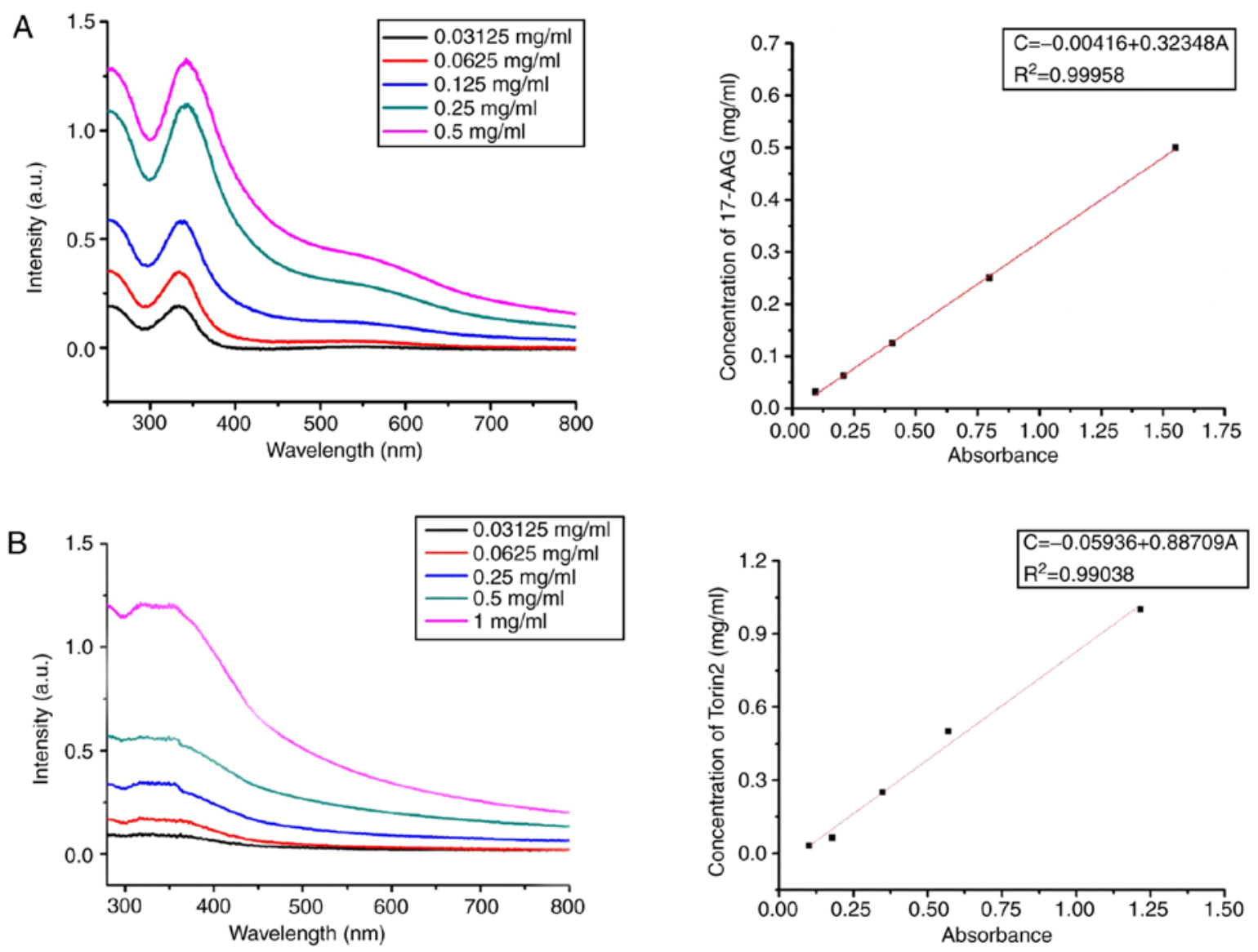

Figure 3. UV-V is absorption wavelength and standard curve of various concentrations of (A) 17-AAG and (B) Torin2, respectively. 17-AAG, 17-allylamino-17-demethoxy-geldanamycin; Torin2 9-(6-aminopyridin-3-yl)-1-(3-(trifluoromethyl)phenyl)benzo[h][1,6]naphthyridin-2(1H)-one; VEGFR2, vascular endothelial growth factor receptor 2 . 

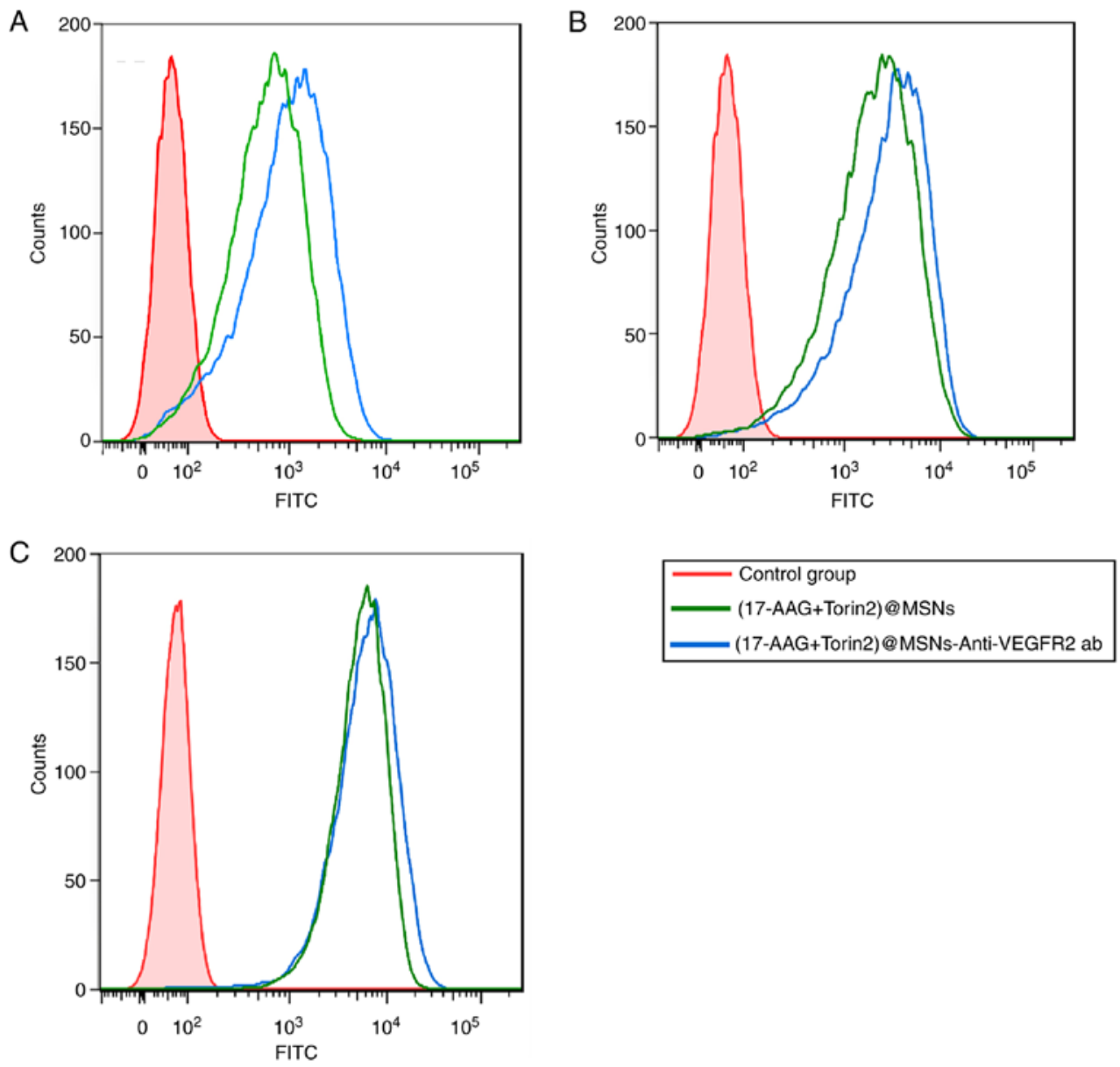

Figure 4. Flow cytometric analysis of (A) FRO cells incubated with (17-AAG+Torin2)@MSNs or (17-AAG+Torin2)@MSNs-anti-VEGFR2 ab for 0.5 h, respectively. (B) FRO cells incubated with (17-AAG+Torin2)@MSNs or (17-AAG+Torin2)@MSNs-anti-VEGFR2 ab for 3 h, respectively. (C) FRO cells incubated with (17-AAG+Torin2)@MSNs or (17-AAG+Torin2)@MSNs-anti-VEGFR2 ab for 8 h, respectively. 17-AAG, 17-allylamino-17-demethoxy-geldanamycin; Torin2 9-(6-aminopyridin-3-yl)-1-(3-(trifluoromethyl)phenyl)benzo[h][1,6]naphthyridin-2(1H)-one; VEGFR2, vascular endothelial growth factor receptor 2.
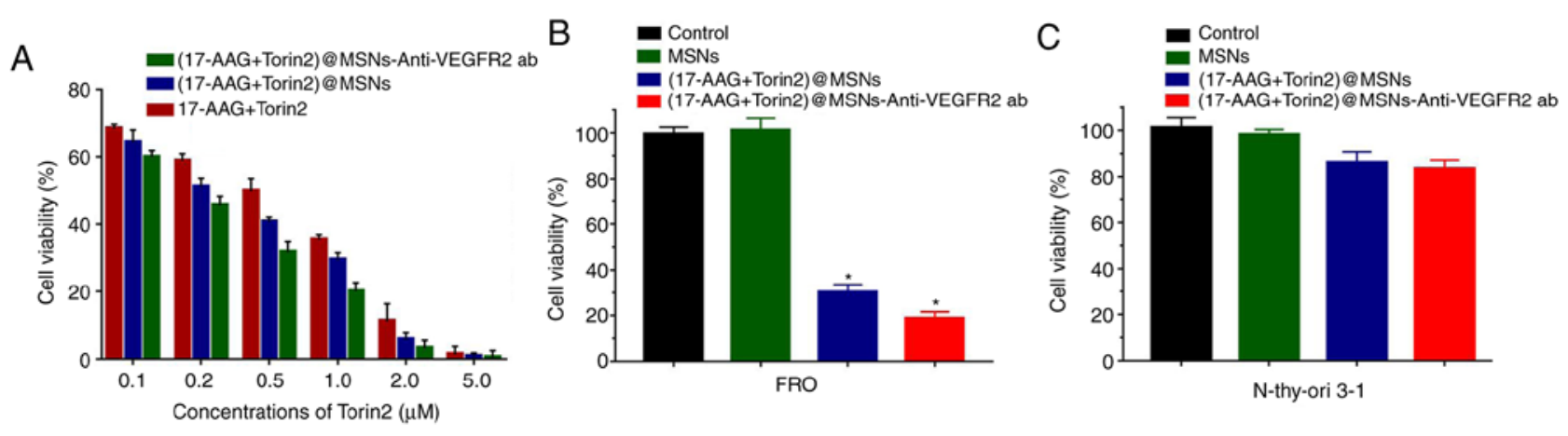

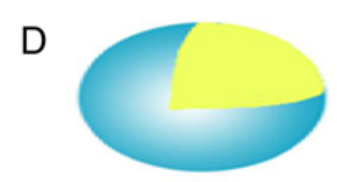

MSNs

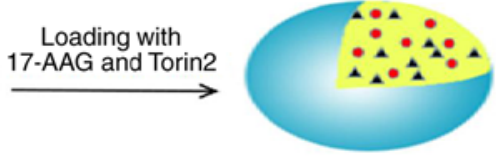

(17-AAG+Torin2)@MSNs

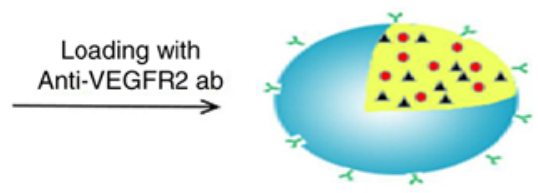

(17-AAG+Torin2)@MSNs-Anti-VEGFR2 ab

17-AAG
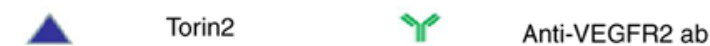

Figure 5. Cellular cytotoxicity of (17-AAG+Torin2)@MSNs-anti-VEGFR2 ab in vitro. (A) FRO cells were incubated with various concentrations of free drugs, and drugs loaded into either MSNs or MSNs-anti-VEGFR2 ab for $48 \mathrm{~h}$. (B and C) FRO, and N-thy-ori 3-1 cell lines were incubated with control medium (Control), MSNs, (17-AAG+Torin2)@MSNs, (17-AAG+Torin2)@MSNs-Anti-VEGFR2 ab for $48 \mathrm{~h}$ (the concentration of 17-AAG or Torin2 was $1 \mu \mathrm{M}$, respectively). (D) Schematic illustration of the synthesis process of the (17-AAG+Torin2)@MSNs-anti-VEGFR2 ab. *P<0.05. 17-AAG, 17-allylamino-17-demethoxy-geldanamycin; Torin2 9-(6-aminopyridin-3-yl)-1-(3-(trifluoromethyl)phenyl)benzo[h][1,6]naphthyridin-2(1H)-one; VEGFR2, vascular endothelial growth factor receptor 2 . 
Table IV. Viability of FRO Cells treated with various concentrations of nano-drug carriers at $48 \mathrm{~h}(\mathrm{mean} \pm \mathrm{SD}, \%)$.

\begin{tabular}{lcccccc}
\hline Concentration $(\mu \mathrm{M})$ & $\mathrm{A}$ & $\mathrm{B}$ & $\mathrm{C}$ & $\mathrm{F}(\mathrm{P}-\mathrm{value})^{\mathrm{b}}$ & $\mathrm{tA}_{\mathrm{A}: \mathrm{B}(\mathrm{P}-\mathrm{value})^{\mathrm{c}}} \mathrm{tB}: \mathrm{C}(\mathrm{P}-\mathrm{value})^{\mathrm{c}}$ \\
\hline 0.1 & $68.36 \pm 1.24$ & $64.24 \pm 3.67$ & $59.88 \pm 2.01$ & $17.00(<0.01)$ & $2.61(<0.05)$ & $2.55(<0.05)$ \\
0.2 & $58.79 \pm 2.14$ & $51.11 \pm 2.58$ & $45.39 \pm 2.78$ & $42.91(<0.01)$ & $5.61(<0.01)$ & $3.69(<0.01)$ \\
0.5 & $49.89 \pm 3.69$ & $40.69 \pm 1.32$ & $31.68 \pm 3.15$ & $59.03(<0.01)$ & $5.75(<0.01)$ & $6.46(<0.01)$ \\
1 & $35.41 \pm 1.47$ & $29.38 \pm 2.21$ & $19.97 \pm 2.68$ & $76.60(<0.01)$ & $5.56(<0.01)$ & $6.64(<0.01)$ \\
2 & $11.13 \pm 5.21$ & $5.57 \pm 2.07$ & $3.25 \pm 2.34$ & $7.91(<0.01)$ & $2.35(<0.05)$ & $1.96(0.76)$ \\
5 & $1.37 \pm 2.40$ & $0.79 \pm 1.01$ & $0.49 \pm 2.01$ & $0.33(<0.01)$ & $0.55(0.62)$ & $0.33(0.69)$ \\
\hline
\end{tabular}

A, (17-AAG+Torin2) group; B, (17-AAG+Torin2)@MSNs group; C, (17-AAG+Torin2)@MSNs-Anti-VEGFR2 ab group. ${ }^{\mathrm{a} T h e}$ concentration of Torin2; banalyzed by analysis of variance; 'analyzed by Student's t-test. 17-AAG, 17-allylamino-17-demethoxy-geldanamycin; Torin2, 9-(6-aminopyridin-3-yl)-1-(3-(trifluoromethyl)phenyl)benzo[h][1,6]naphthyridin-2(1H)-one.
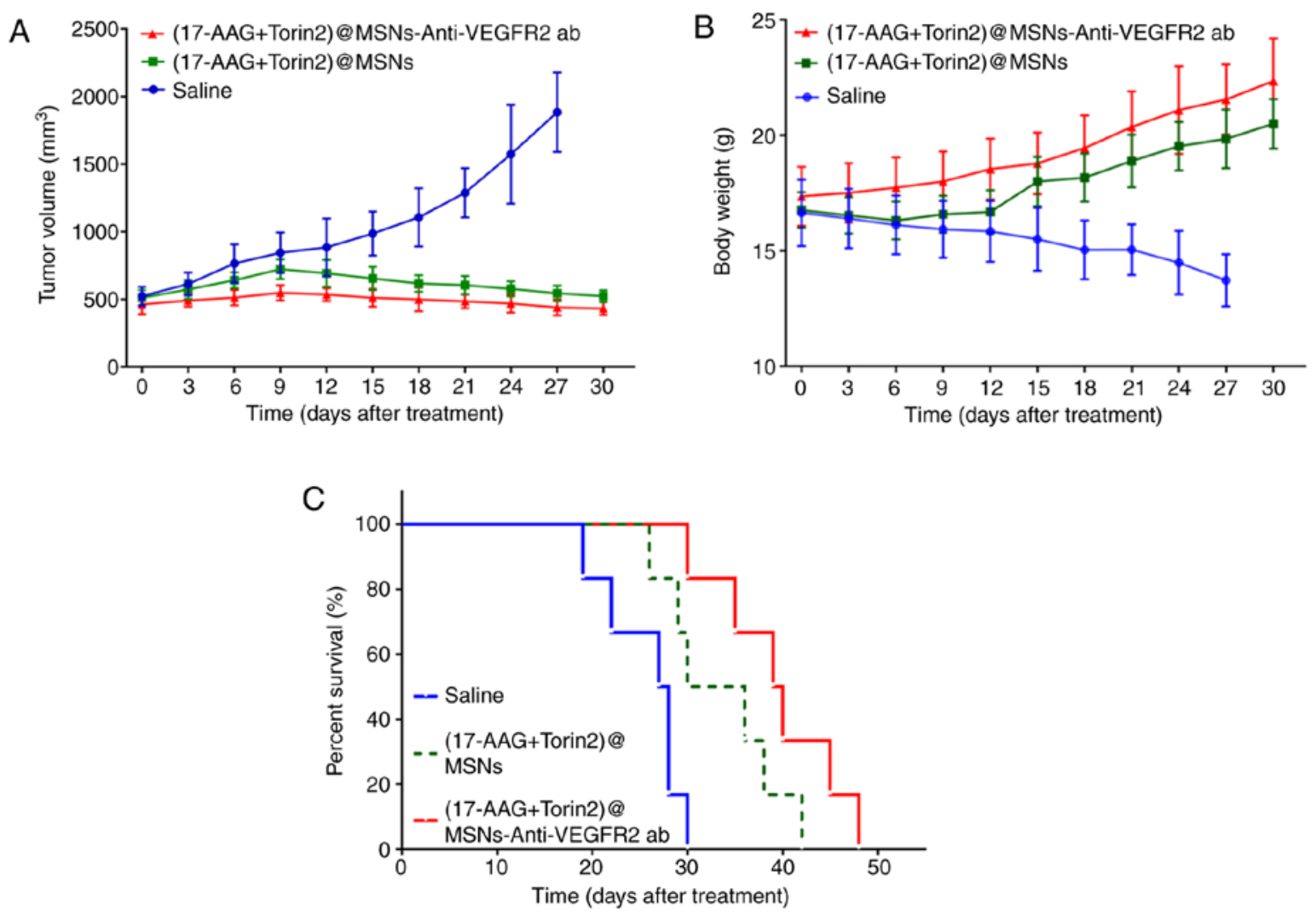

Figure 6. Anticancer effects of (17-AAG+Torin2)@MSNs-anti-VEGFR2 ab and (17-AAG+Torin2)@MSNs in FRO tumor xenograft mice. (A) The tumor volume changes, (B) the body weight changes, and (C) the Kaplan-Meier survival curves in the tumor xenograft mice (n=6/group). 17-AAG, 17-allylamino-17-demethoxy-geldanamycin; Torin2 9-(6-aminopyridin-3-yl)-1-(3-(trifluoromethyl)phenyl)benzo[h][1,6]naphthyridin-2(1H)-one; VEGFR2, vascular endothelial growth factor receptor 2 .

specificity of (17-AAG+Torin2)@MSNs-anti-VEGFR2 ab on VEGFR2-positive cells and the low cytotoxicity on normal cells (Fig. 5D).

In vivo effects of (17-AAG+Torin2)@MSNs-Anti-VEGFR2 ab on tumor growth in tumor xenograft mice. The changes in the tumor volumes of the three groups were revealed in Fig. 6A. Significant inhibition of tumor growth was observed in animals treated with (17-AAG+Torin2)@MSNs-anti-VEGFR2 ab. The tumor volume of mice treated with (17-AAG+Torin2)@ MSNs-anti-VEGFR2 ab were significantly different from the mice treated with normal saline or (17-AAG+Torin2)@MSNs, indicating that (17-AAG+Torin2)@MSNs-anti-VEGFR2 ab could inhibit tumor growth more effectively. Rapid body weight losses were observed in the xenografted ATC nude mice treated with normal saline. By contrast, the body weight increased in mice treated with (17-AAG+Torin2)@MSNs or (17-AAG+Torin2)@MSNs-anti-VEGFR2 ab, especially for the group treated with (17-AAG+Torin2)@MSNs-anti-VEGFR2 ab (Fig. 6B). The Kaplan-Meier survival curves of all study groups are presented in Fig. 6C. The median survival time of those three groups (treated with normal saline, treated 

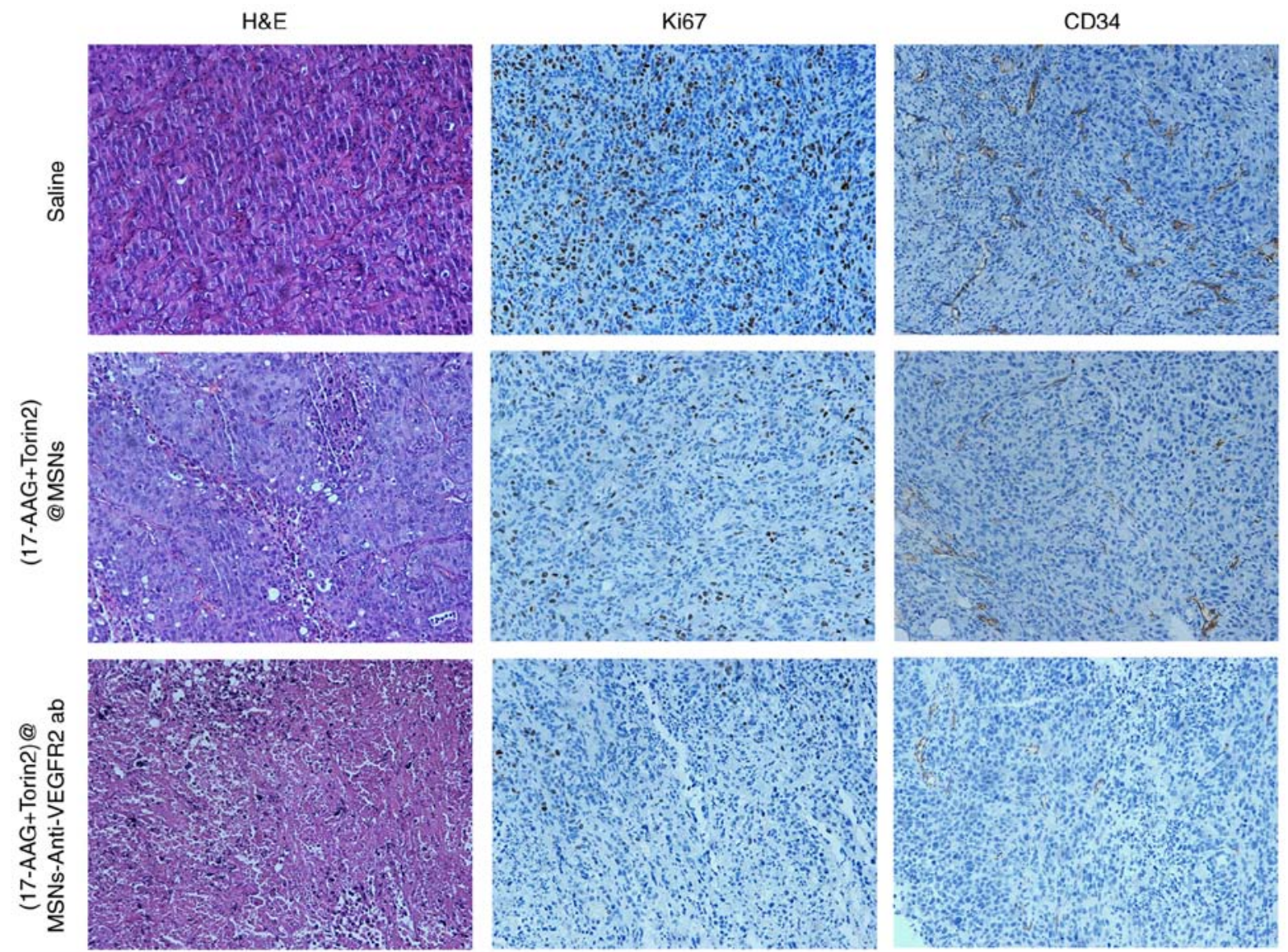

Figure 7. Histopathological and immunohistochemical (H\&E) analysis.

with (17-AAG+Torin2)@MSNs, and (17-AAG+Torin2)@ MSNs-Anti-VEGFR2 ab was 27.5, 33, and 39.5 days, respectively. Additionally, analysis via a log-rank test verified that the median survival time in the group treated with the (17-AAG+Torin2)@MSNs-anti-VEGFR2 ab was significantly prolonged compared with the group treated with (17-AAG+Torin2)@MSNs or normal saline (all $\mathrm{P}<0.01$ ).

Histopathological and immunohistochemistry analysis. In order to evaluate the antitumor effect of (17-AAG+Torin2)@ MSNs-anti-VEGFR2 ab in vivo, the H\&E staining sections of various experimental groups under light microscope were observed. The tumors treated with (17-AAG+Torin2)@ MSNs and (17-AAG+Torin2)@MSNs-anti-VEGFR2 ab both revealed necrosis and degeneration of tumor cells, whereas the latter induce more necrosis of tumor cells. However, no significant pathological changes in tumors were observed after treatment with saline group (Fig. 7). Decreased expression of Ki-67 and CD34 was observed in the (17-AAG+Torin2)@ MSNs and (17-AAG+Torin2)@MSNs-anti-VEGFR2 ab group, which indicated the suppression of tumor cell proliferation and the effective inhibition of vascularization in the (17-AAG+Torin2)@MSNs-anti-VEGFR2 ab group and the (17-AAG+Torin2)@MSNs group, compared to the saline group (Fig. 7). Additionally, the results from the histopathology and immunohistochemistry revealed that (17-AAG+Torin2)@ MSNs-anti-VEGFFR2 ab could more effectively inhibit tumor progression in vivo than (17-AAG+Torin2)@MSNs.

\section{Discussion}

Anaplastic thyroid carcinoma (ATC) is a rare and fatal malignancy that almost always spreads simultaneously at the time of diagnosis. However, ATC has a very poor prognosis due to its resistance to traditional thyroid cancer treatments, including the suppression of TSH and radioiodine. Nowadays, targeted molecular therapy, as a new treatment method, has become the important treatment in reducing the morbidity and mortality of the malignancy (4).

HSP90, as a molecular chaperone protein, is expressed in tumor cells 2- to 10-fold higher than normal cells $(37,38)$. It is an important component of numerous oncogene pathways and plays an important role in regulating the growth and survival of tumor cells. Mechanistically, 17-AAG binds to the ATP-binding sac at the amino terminus of HSP90, to inhibit HSP90 function. Moreover, 17-AAG also inhibits phosphatidylinositol-3 kinase cascades and MAPK $(14,39)$. Recently, research has demonstrated that thyroid carcinoma cell lines are sensitive to 17-AAG. The sensitivity of this agent to cytotoxicity was revealed to be related to the level of HSP90 expression in thyroid carcinoma cell lines and the loss of AKT which is the direct target of HSP90 $(38,40)$. In the present study, 17-AAG had the ability to significantly inhibit the proliferation of FRO cells in a time- and dose-dependent manner, which expounds the antitumor effects of 17-AAG on ATC. An increasing amount of research has revealed that Torin 2 inhibits the proliferation and migration 
of tumor cells by inhibiting the phosphorylation of AKT and thereby blocking the PI3K/AKT/mTOR signal transduction pathway (41-43). Sadowski et al (41) demonstrated that the mTOR pathway was upregulated in ATC, and Torin2 inhibited the phosphorylation of mTOR pathway-related proteins and mTORC1 (phospho-4E-BP1, total 4E-BP1, and phpspho-PRAS40) in a dose-dependent manner. In addition, De Raedt et al (44), revealed that 17-AAG could increase the cytotoxicity of mTOR inhibitors by acting on a compensatory pathway associated with AKT activation. Compared with single treatments, the low dose of 17-AAG combined with Torin 2 could lead to higher cytotoxicity. Using CompuSyn software analysis, it was concluded that synergistic effects occurred $(\mathrm{CI}<1)$ in FRO cells when the total concentrations of the two drugs was $>0.52 \mu \mathrm{M}$ (the rate of 17-AAG and Torin2 was $1: 1$ ) or $0.79 \mu \mathrm{M}$ (the rate of 17-AAG and Torin2 was $2: 1)$. In summary, the coordinate suppression of $17-\mathrm{AAG}$ and Torin 2 on cell proliferation of a human thyroid carcinoma cell line (FRO) was demonstrated.

Nanomaterials have been widely used in the field of biomedicine, including silica, liposomes, polymers, and gold and iron oxide nanoparticles $(4,45)$. Compared to other silica nanomaterials, MSNs are widely used due to their higher surface area, non-toxic property, improved ductility and permeability, adjustable pore structure, chemically modifiable outer surface, and improved biological compatibility $(45,46)$. Additionally, MSNs exhibited improved stability and drug loading capacity, remained for a longer time in the reticuloendothelial system compared to polymeric nanoparticles or liposomes, and performed improved controlled drug release when compared with gold and iron oxide nanoparticles $(45,46)$. In the present study, (17-AAG+Torin2)@MSNs-anti-VEGFR2 ab, a novel VEGFR2-targeted nanoparticle, based on MSNs which improves the concentration of drugs in tumor sites was reported. The process of preparing (17-AAG+Torin2)@ MSNs-Anti-VEGFR2 ab was presented. Through a targeting mechanism for VEGFR2, the present (17-AAG+Torin2)@ MSNs-anti-VEGFR2 ab are expected to target VEGFR2 of thyroid cancer cells and then deliver drugs into cells. Hsiao etal (35) confirmed that the high expression of the VEGFR protein was associated with the risk of spread of the thyroid cancer cells. As a result, a flow cytometric study was employed in the present study to observe whether the anti-VEGFR2 antibody maintains its binding specificity and affinity for VEGFR2 in combination with MSNs. Concurrently, the cell uptake of nanoparticles could be observed. The high binding and uptake of (17-AAG+Torin2)@MSNs-anti-VEGFR2 ab by FRO cells further confirmed the overexpression of VEGFR2 on the surface of anaplastic thyroid carcinoma cells and the function of the anti-VEGFR2 antibody was not destroyed.

In the present study, the efficacies of (17-AAG+Torin2)@ MSNs and (17-AAG+Torin2)@MSNs-anti-VEGFR2 ab for the therapy of anaplastic thyroid carcinoma in vivo and in vitro was estimated. As revealed in Fig. 6, the results confirmed that both (17-AAG+Torin2)@MSNs and (17-AAG+Torin2)@MSNs-anti-VEGFR2 ab were effective in inhibiting the growth of ATC and that the (17-AAG+Torin2)@ MSNs-anti-VEGFR2 ab exhibited more significant inhibition of ATC. Histopathological and immunohistochemical studies confirmed that tumors treated with the (17-AAG + Torin2)@
MSNs-anti-VEGFR2 ab group had degeneration and massive necrosis of tumor cells, cell proliferation and angiogenesis were evidently decreased, however, the specific mechanism was still unclear.

Some studies have reported that direct intra-tumoral injection is clearly appealing in the treatment of neck and head tumors $(47,48)$. In the present study, intra-tumoral drug administration was used, which achieved a high drug concentration at the target sites and few side effects of systemic chemotherapy with a convenient operation. However, the clinical application of intra-tumoral drugs has slowed down recently due to its limitations, especially since primary tumors are easier to remove by surgery. However, for the treatment of metastatic or inoperable diseases, systemic treatment is necessary (49).

In this systematic research, the toxic effects of 17-AAG and Torin2 on FRO cells were mainly studied, using MSNs as a more efficient drug delivery system. However, there are a few limitations in the present study. Firstly, the expression levels of HSP90, VEGFR2 and p-mTOR were not determined using western blot or RT-PCR assays although research has confirmed that their expression levels were high in ATC cells. However, the exact mechanism of the crosstalk between 17-AAG and Torin2 is still unclear. Secondly, although the present study provided favorable results using the FRO cell line, a non-metastatic cell line, further research should in fact be performed to verify/compare the results in other ATC cells or VEGFR-negative carcinoma cells. Thirdly, the safety of the delivery was verified in only one normal cell line, further experiments should be performed on additional normal cells (both VEGFR-positive and -negative).

In conclusion, the present study confirmed that (17-AAG+Torin2)@MSNs-anti-VEGFR2 ab exhibited great advantages in loading anticancer drugs, and is expected to play a significant role in killing tumor cells and becoming a new method for treating ATC.

\section{Acknowledgements}

Not applicable.

\section{Funding}

The present study was supported by grants from the National Natural Science Foundation of China (nos. 81501510 and 81801732).

\section{Availability of data and materials}

The datasets used during the present study are available from the corresponding author upon reasonable request.

\section{Authors' contributions}

$\mathrm{CW}, \mathrm{RZ}$ and RW conceived and designed the study. CW, $\mathrm{YZ}, \mathrm{NL}$ and $\mathrm{HW}$ performed the experiments. $\mathrm{CW}, \mathrm{RZ}$ and RW wrote the paper. JT, ZM and JC reviewed and edited the manuscript. All authors read and approved the final manuscript. All authors read and approved the final manuscript and agree to be accountable for all aspects of the research in 
ensuring that the accuracy or integrity of any part of the work are appropriately investigated and resolved.

\section{Ethics approval and consent to participate}

All animal experimental procedures were performed with strict accordance with guidelines approved by the Institutional Animal Experiments Ethics Committee of Tianjin Medical University General Hospital.

\section{Patient consent for publication}

Not applicable.

\section{Competing interests}

The authors declare that they have no competing interests.

\section{References}

1. Valerio L, Pieruzzi L, Giani C, Agate L, Bottici V, Lorusso L, Cappagli V, Puleo L, Matrone A, Viola D, et al: Targeted therapy in thyroid cancer: State of the art. Clin Oncol (R Coll Radiol) 29 316-324, 2017.

2. Hsu KT, Yu XM, Audhya AW, Jaume JC, Lloyd RV, Miyamoto S, Prolla TA and Chen H: Novel approaches in anaplastic thyroid cancer therapy. Oncologist 19: 1148-1155, 2014.

3. Neff RL, Farrar WB, Kloos RT and Burman KD: Anaplastic thyroid cancer. Endocrinol Metab Clin North Am 37: 525-538, 2008.

4. Zhang R, Zhang Y, Tan J, Wang H, Zhang G, Li N, Meng Z, Zhang F, Chang J and Wang R: Antitumor effect of ${ }^{131}$ I-Labeled Anti-VEGFR2 targeted mesoporous silica nanoparticles in anaplastic thyroid cancer. Nanoscale Res Lett 14: 96, 2019.

5. Cabanillas ME, Zafereo M, Gunn GB and Ferrarotto R: Anaplastic thyroid carcinoma: Treatment in the age of molecular targeted therapy. J Oncol Pract 12: 511-518, 2016.

6. O'Neill JP, Power D, Condron C, Bouchier-Hayes D and Walsh M: Anaplastic thyroid cancer, tumorigenesis and therapy. Ir J Med Sci 179: 9-15, 2010.

7. Sawada M, Oishi T, Komatsu H, Sato S, Chikumi J, Nonaka M, Kudoh A, Osaku D and Harada T: Serum vascular endothelial growth factor A and vascular endothelial growth factor receptor 2 as prognostic biomarkers for uterine cervical cancer. Int J Clin Oncol 24: 1612-1619, 2019.

8. Brands RC, Knierim LM, De Donno F, Steinacker V, Hartmann S, Seher A, Kübler AC and Müller-Richter UDA: Targeting VEGFR and FGFR in head and neck squamous cell carcinoma in vitro. Oncol Rep 38: 1877-1885, 2017.

9. Costache MI, Ioana M, Iordache S, Ene D, Costache CA and Săftoiu A: VEGF expression in pancreatic cancer and other malignancies: A review of the literature. Rom J Intern Med 53: 199-208, 2015

10. Jolly $\mathrm{C}$ and Morimoto RI: Role of the heat shock response and molecular chaperones in oncogenesis and cell death. J Natl Cancer Inst 92: 1564-1572, 2000.

11. Porter JR, Fritz CC and Depew KM: Discovery and development of Hsp90 inhibitors: A promising pathway for cancer therapy. Curr Opin Chem Biol 14: 412-420, 2010.

12. Kim YS, Alarcon SV, Lee S, Lee MJ, Giaccone G, Neckers L and Trepel JB: Update on Hsp90 inhibitors in clinical trial. Curr Top Med Chem 9: 1479-1492, 2009.

13. Maloney A and Workman P: HSP90 as a new therapeutic target for cancer therapy: The story unfolds. Expert Opin Biol Ther 2: 3-24, 2002.

14. Kim SH, Kang JG, Kim CS, Ihm SH, Choi MG, Yoo HJ and Lee SJ: 17-Allylamino-17-demethoxygeldanamycin and Herbimycin A Induce Cell Death by modulating beta-Catenin and PI3K/AKT signaling in FRO anaplastic thyroid carcinoma cells. Anticancer Res 35: 5453-5460, 2015.

15. White PT, Subramanian C, Zhu Q, Zhang H, Zhao H, Gallagher R, Timmermann BN, Blagg BS and Cohen MS: Novel HSP90 inhibitors effectively target functions of thyroid cancer stem cell preventing migration and invasion. Surgery 159: 142-151, 2016.
16. Ahmed M, Hussain AR, Bavi P, Ahmed SO, Al Sobhi SS, Al-Dayel F, Uddin S and Al-Kuraya KS: High prevalence of mTOR complex activity can be targeted using Torin 2 in papillary thyroid carcinoma. Carcinogenesis 35: 1564-1572, 2014.

17. Beauchamp EM and Platanias LC: The evolution of the TOR pathway and its role in cancer. Oncogene 32: 3923-3932, 2013.

18. Tavares C, Eloy C, Melo M, Gaspar da Rocha A, Pestana A, Batista R, Bueno Ferreira L, Rios E, Sobrinho Simões M and Soares P: mTOR pathway in papillary thyroid carcinoma: Different contributions of mTORC1 and mTORC 2 complexes for tumor behavior and SLC5A5 mRNA expression. Int J Mol Sci 19: pii: E1448, 2018.

19. Faustino A, Couto JP, Pópulo H, Rocha AS, Pardal F, Cameselle-Teijeiro JM, Lopes JM, Sobrinho-Simões M and Soares P: mTOR pathway overactivation in BRAF mutated papillary thyroid carcinoma. J Clin Endocrinol Metab 97: E1139-E1149, 2012.

20. Sidera K and Patsavoudi E: HSP90 inhibitors: Current development and potential in cancer therapy. Recent Pat Anticancer Drug Discov 9: 1-20, 2014.

21. Chen Y, Chen H and Shi J: In vivo bio-safety evaluations and diagnostic/therapeutic applications of chemically designed mesoporous silica nanoparticles. Adv Mater 25: 3144-3176, 2013.

22. Rosenholm JM, Mamaeva V, Sahlgren C and Lindén M: Nanoparticles in targeted cancer therapy: Mesoporous silica nanoparticles entering preclinical development stage. Nanomedicine (Lond) 7: 111-120, 2012.

23. Benezra M, Penate-Medina O, Zanzonico PB, Schaer D, Ow H, Burns A, DeStanchina E, Longo V, Herz E, Iyer S, et al: Multimodal silica nanoparticles are effective cancer-targeted probes in a model of human melanoma. J Clin Invest 121: 2768-2780, 2011.

24. Tang F, Li L and Chen D: Mesoporous silica nanoparticles: Synthesis, biocompatibility and drug delivery. Adv Mater 24: 1504-1534, 2012

25. Naz S, Shamoon M, Wang R, Zhang L, Zhou J and Chen J: Advances in therapeutic implications of inorganic drug delivery Nano-platforms for cancer. Int J Mol Sci 20: pii: E965, 2019.

26. Goel S, Chen F, Hong H, Valdovinos HF, Hernandez R, Shi S, Barnhart TE and Cai W: $\mathrm{VEGF}_{121}$-conjugated mesoporous silica nanoparticle: A tumor targeted drug delivery system. ACS Appl Mater Interfaces 6: 21677-21685, 2014

27. Tran VA and Lee SW: A prominent anchoring effect on the kinetic control of drug release from mesoporous silica nanoparticles (MSNs). J Colloid Interface Sci 510: 345-356, 2018.

28. Ghalhar MG, Akbarzadeh A, Rahmati M, Mellatyar H, Dariushnejad H, Zarghami N and Barkhordari A: Comparison of inhibitory effects of 17-AAG nanoparticles and free 17-AAG on HSP90 gene expression in breast cancer. Asian Pac J Cancer Prev 15: 7113-7118, 2014

29. Xu Y, Zhang C, Chen D, Zhao J, Shen Z, Wu Y and Zhu Y: Effect of HSP90 inhibitor in pheochromocytoma PC12 cells: An experimental investigation. Tumour Biol 34: 4065-4071, 2013.

30. Chou TC: Drug combination studies and their synergy quantification using the Chou-Talalay method. Cancer Res 70: 440-446, 2010.

31. Liang C, Wang H, Zhang M, Cheng W, Li Z, Nie J, Liu G, Lian D, Xie Z, Huang L and Zeng X: Self-controlled release of Oxaliplatin prodrug from $\mathrm{d}-\alpha$-tocopheryl polyethylene glycol 1000 succinate (TPGS) functionalized mesoporous silica nanoparticles for cancer therapy. J Colloid Interface Sci 525: $1-10,2018$.

32. Mortensen JH, Jeppesen M, Pilgaard L, Agger R, Duroux M, Zachar V and Moos T: Targeted antiepidermal growth factor receptor (cetuximab) immunoliposomes enhance cellular uptake in vitro and exhibit increased accumulation in an intracranial model of glioblastoma multiforme. J Drug Deliv 2013: 209205, 2013.

33. Reddi HV, Driscoll CB, Madde P, Milosevic D, Hurley RM, McDonough SJ, Hallanger-Johnson J, McIver B and Eberhardt NL: Redifferentiation and induction of tumor suppressors miR-122 and miR-375 by the PAX8/PPARgamma fusion protein inhibits anaplastic thyroid cancer: A novel therapeutic strategy. Cancer Gene Ther 20: 267-275, 2013.

34. Kim H, Kim SW, Seok KH, Hwang CW, Ahn JC, Jin JO and Kang HW: Hypericin-assisted photodynamic therapy against anaplastic thyroid cancer. Photodiagnosis Photodyn Ther 24: 15-21, 2018. 
35. Hsiao PJ, Lu MY, Chiang FY, Shin SJ, Tai YD and Juo SH: Vascular endothelial growth factor gene polymorphisms in thyroid cancer. J Endocrinol 195: 265-270, 2007.

36. Soh EY, Duh QY, Sobhi SA, Young DM, Epstein HD, Wong MG, Garcia YK, Min YD, Grossman RF, Siperstein AE and Clark OH: Vascular endothelial growth factor expression is higher in differentiated thyroid cancer than in normal or benign thyroid. J Clin Endocrinol Metab 82: 3741-3747, 1997.

37. Ferrarini M, Heltai S, Zocchi MR and Rugarli C: Unusual expression and localization of heat-shock proteins in human tumor cells. Int J Cancer 51: 613-619, 1992.

38. Banerji U, Judson I and Workman P: The clinical applications of heat shock protein inhibitors in cancer-present and future. Curr Cancer Drug Targets 3: 385-390, 2003.

39. Braga-Basaria M, Hardy E, Gottfried R, Burman KD, Saji M and Ringel MD: 17-Allylamino-17-demethoxygeldanamycin activity against thyroid cancer cell lines correlates with heat shock protein 90 levels. J Clin Endocrinol Metab 89: 2982-2988, 2004.

40. Sato S, Fujita $\mathrm{N}$ and Tsuruo T: Modulation of Akt kinase activity by binding to Hsp90. Proc Natl Acad Sci USA 97: 10832-10837, 2000

41. Sadowski SM, Boufraqech M, Zhang L, Mehta A, Kapur P, Zhang Y, Li Z, Shen M and Kebebew E: Torin2 targets dysregulated pathways in anaplastic thyroid cancer and inhibits tumor growth and metastasis. Oncotarget 6: 18038-18049, 2015

42. Courtney KD, Corcoran RB and Engelman JA: The PI3K pathway as drug target in human cancer. J Clin Oncol 28: 1075-1083, 2010.

43. Milosevic Z, Pesic M, Stankovic T, Dinic J, Milovanovic Z, Stojsic J, Dzodic R, Tanic N and Bankovic J: Targeting RAS-MAPK-ERK and PI3K-AKT-mTOR signal transduction pathways to chemosensitize anaplastic thyroid carcinoma. Transl Res 164: 411-423, 2014.
44. De Raedt T, Walton Z, Yecies JL, Li D, Chen Y, Malone CF, Maertens O, Jeong SM, Bronson RT, Lebleu V, et al: Exploiting cancer cell vulnerabilities to develop a combination therapy for ras-driven tumors. Cancer Cell 20: 400-413, 2011.

45. Zhang L, Gu FX, Chan JM, Wang AZ, Langer RS and Farokhzad OC: Nanoparticles in medicine: Therapeutic applications and developments. Clin Pharmacol Ther 83: 761-769, 2008.

46. Yang $\mathrm{Y}$ and $\mathrm{Yu} \mathrm{C}$ : Advances in silica based nanoparticles for targeted cancer therapy. Nanomedicine 12: 317-332, 2016.

47. So Y, Lee YJ, Lee WW and Chung JK: Determination of the optimal time for radioiodine therapy in anaplastic thyroid carcinoma using the adenovirus-mediated transfer of sodium iodide symporter gene. Oncol Rep 29: 1666-1670, 2013

48. Zhou M, Chen Y, Adachi M, Wen X, Erwin B, Mawlawi O, Lai SY and Li C: Single agent nanoparticle for radiotherapy and radio-photothermal therapy in anaplastic thyroid cancer. Biomaterials 57: 41-49, 2015.

49. Mirzaei-Parsa MJ, Najafabadi MRH, Haeri A,Zahmatkeshan M, Ebrahimi SA, Pazoki-Toroudi $\mathrm{H}$ and Adel M: Preparation, characterization, and evaluation of the anticancer activity of Artemether-loaded Nano-Niosomes against breast cancer. Breast Cancer 27: 243-251, 2020. 